\title{
Case-Control Study of Risk Factors for Surgical Site Infection After Three-column Osteotomy for Spine Deformity
}

\author{
Rafael DE LA GARZA RAMOS ${ }^{1,2}$, Jonathan NAKHLA ${ }^{1,2}$, Rani NASSER ${ }^{1,2}$, Niketh BHASHYAM ${ }^{1}$, Merrit D. KINON ${ }^{1,2}$, \\ Reza YASSARI ${ }^{1,2}$ \\ ${ }^{1}$ Montefiore Medical Center/Albert Einstein College of Medicine, Spine Research Group, Bronx, New York, USA \\ ${ }^{2}$ Montefiore Medical Center/Albert Einstein College of Medicine, Department of Neurological Surgery, Bronx, New York, USA
}

\section{ABSTRACT}

AIM: To investigate risk factors for surgical site infection (SSI) after three-column osteotomy (3CO) for spinal deformity.

MATERIAL and METHODS: The American College of Surgeons National Surgical Quality Improvement Program database (20122014) was reviewed. We included adult patients who underwent $3 \mathrm{CO}$ and compared pertinent cases (SSI) to controls (no SSI) in terms of preoperative and operative characteristics. Patients with clean/contaminated, contaminated, and dirty/infected wounds were excluded. A stepwise multivariate regression was used to identify independent predictors of SSI, with results presented as odds ratios (OR) with $95 \%$ confidence intervals $(\mathrm{Cl})$.

RESULTS: There were 293 patients who underwent 3CO for spinal deformity, out of whom 15 (5.1\%) developed a SSI during the 30day follow-up period. Of the 15 patients with SSI, 10 underwent reoperation (66.7\%) within 30 days. Compared to controls, patients in the SSI group were more likely to be obese $(p=0.030)$, have a higher American Society of Anesthesiologists (ASA) physical status class $(p=0.051)$ and be more likely to undergo multilevel $3 C O(p=0.013)$. After controlling for obesity, bleeding disorder, deformity type, ASA class, preoperative anemia, and multilevel procedures, Class II obesity (OR 4.98; 95\% Cl, 1.24 - 19.94; $p=0.023$ ) and multilevel 3CO (OR 4.71; 95\% Cl, $1.30-16.94 ; \mathrm{p}=0.018$ ) were significant predictors of SSI occurrence.

CONCLUSION: Patients with Class II obesity and patients who undergo multilevel osteotomy may be at a significantly increased risk of developing a SSI within 30 days after $3 \mathrm{CO}$ for spine deformity.

KEYWORDS: National Surgical Quality Improvement Program, Spinal deformity, Surgical site infection, Three-column osteotomy

\section{INTRODUCTION}

S pinal three-column osteotomy $(3 \mathrm{CO})$ is an aggressive surgical technique used, among others, in cases of severe focal kyphoscoliosis and iatrogenic fixed sagittal imbalance $(8,24,28)$. These techniques involve both vertebral column resection and pedicle subtraction osteotomy, which allow for up to 30-40 degrees of correction per level. Although favorable outcomes can be achieved in restoring global spinal alignment $(8,10,12,17,22,27)$, complication rates have been reported to be as high as $59 \%$ (14). These complications include both short- and long-term adverse events such as spinal cord deficit, nerve root injury, deep vein thrombosis, surgical site infection (SSI), instrumentation failure, adjacent segment disease, and others (2).

SSI is of particular concern given its association with higher rates of readmission, reoperation for possible wound washout, postoperative morbidity, and overall increased hospital resource utilization $(1,3,18,21)$. In a systematic review of complications after deformity surgery, the authors found an overall estimated rate of SSI of $2.4 \%$, which increased to $3.2 \%$ for $3 \mathrm{CO}$ procedures (23). Factors that have been associated with SSI development after deformity surgery include obesity, 
history of previous SSI, long operations, and diabetes, among others $(20,21)$.

Although multiple studies have examined outcomes after $3 \mathrm{CO}$, there is limited data on factors associated with SSI, particularly on a national level. Hence, the purpose of the present study was to identify risk factors for SSI after $3 \mathrm{CO}$ for complex spine deformity using a large prospective database.

\section{- MATERIAL and METHODS}

\section{Study Design and Data Source}

This is a retrospective case-control study using prospectively collected data for patients who underwent $3 \mathrm{CO}$ for complex spinal deformity between 2012 and 2014. Data was reviewed from the American College of Surgeons National Surgical Quality Improvement Program (NSQIP) database, which contains data from patients who undergo major surgical procedures from over 370 hospitals in the United States. Patients are randomly selected to be captured in the database, and a trained "Surgical Clinical Reviewer" is in charge of prospectively collecting preoperative, intraoperative, and postoperative data up to 30 days after the main procedure. This database uses Current Procedural Terminology (CPT) procedural codes and of International Classification of Diseases, $9^{\text {th }}$ Revision (ICD-9) diagnostic codes (www.facs/ org/quality-programs/acs-nsqip). Given that the database contains only de-identified information, this study was exempt from review by the local institutional review board (IRB\#20166862).

For identification of the study population, CPT code 22206 was used to identify thoracic $3 \mathrm{CO}$ and 22207 to identify lumbar 3CO; multilevel procedures were identified via use of code 22208. Patients with wounds classified as clean/ contaminated, contaminated, or dirty/infected were excluded $(\mathrm{n}=6)$.

\section{Collected Variables and Outcome Measures}

Reviewed demographic data included patient age, sex, body mass index (BMI), and co-morbidities such as hypertension, current smoking, diabetes, chronic obstructive pulmonary disease (COPD), chronic steroid use, bleeding disorder, dependent functional status (defined as needing some or full assistance from another person for activities of daily living), American Society of Anesthesiologists (ASA) physical status classification, anemia (defined as hematocrit $<36 \%$ ), and preoperative albumin level. Operative data included need for blood transfusion, operative time, revision status, thoracic vs. lumbar $3 \mathrm{CO}$, single vs. multilevel $3 \mathrm{CO}$, and use of spino-pelvic fixation.

The main outcome measure (cases) was development of SSI during the 30-day follow-up period. SSI included superficial, deep, and organ-space infection, which were analyzed as a single group to increase statistical power.

\section{Statistical Analysis}

Two groups consisting of cases (SSI) and controls (no SSI) were established and compared. Continuous variables were compared via t-tests with unequal variance and frequencies via Pearson's chi-squared or Fisher's exact test as appropriate. Factors with a $p$-value $<0.200$ on univariate analysis were included in a stepwise regression model with backward elimination to identify independent predictors of SSI occurrence; results are presented as odds ratios (OR) with 95\% confidence intervals $(\mathrm{Cl})$. All analyses were performed in Stata SE 12 (StataCorp, College Station, Texas, USA) and statistical significance was defined as a p-value less than 0.05 .

\section{RESULTS}

\section{Patient Characteristics}

A total of 293 patients met the inclusion criteria and were included in this study, out of whom 15 (5.1\%) developed a SSI. Indications for $3 \mathrm{CO}$ included acquired deformity $(72.0 \%)$, iatrogenic deformity $(13.7 \%)$, other deformity $(7.2 \%)$, posttraumatic deformity (4.8\%), and congenital deformity $(2.4 \%)$. Superficial SSI occurred in four patients (1.4\%), deep wound infection in eight cases $(2.7 \%)$, and organ space infection in four cases (1.4\%); one patient initially developed a superficial infection that then progressed to deep wound infection. Average day to occurrence was postoperative day 19 (range: 16 - 25) for superficial SSI, day 23 (range: 13 - 29) for deep wound infection, and day 13 (range: 0 - 30) for organ space SSI. Of the 15 patients with SSI, 10 underwent reoperation $(66.7 \%)$ within 30 days.

Average age at surgery was $57 \pm 14$ years for patients with SSI and $61 \pm 13$ for controls ( $p=0.310)$ (Table I). There was no significant difference in the proportion of males in the SSI (40.0\%) and control group (35.3\%, $p=0.708)$. There were significant differences between the groups based on BMl $(p=0.030)$, with a significantly higher proportion of patients being obese (Class I, II, and III) in the SSI group. Type of deformity $(p=0.698)$ and other co-morbidities, including ASA class, were not significantly different between groups at a $\mathrm{p}$-value of 0.05 .

\section{Operative Characteristics}

Perioperative blood transfusion was used in $73.3 \%$ of patients in the SSI group and $76.6 \%$ of patients in the control group $(p=0.770)$. Mean operative time $(p=0.584)$, revision procedures $(p=0.369)$, thoracic $3 C O(p=1.00)$, or pelvic fixation $(p=0.377)$ was not significant different between the two group of patients. On the other hand, patients in the SSI group were significantly more likely to undergo multilevel $3 \mathrm{CO}$ when compared to controls (40.0\% vs. $13.4 \%, p=0.013)$ (Table II).

\section{Multivariate Analysis}

After controlling for obesity, bleeding disorder, deformity type, ASA class, preoperative anemia, and multilevel procedures, Class II Obesity (OR 4.98; 95\% Cl, $1.24-19.94 ; p=0.023$ ) and multilevel 3CO (OR 4.71; 95\% Cl, 1.30 - 16.94; $\mathrm{p}=0.018$ ) were significant predictors of SSI occurrence (Table III).

\section{DISCUSSION}

Surgical site infection is a particularly concerning complication 
after spine surgery given its association with longer lengths of stay or readmission, increased healthcare costs, association with other complications, and need for revision surgery in some cases (21). 3COs are procedures used to treat severe and/or fixed spinal deformities, but carry the risk of major perioperative complications, including wound infection $(2,13)$. The purpose of this study was to identify the rate of SSI after $3 \mathrm{CO}$, and to identify risk factors for their occurrence; we found a $5.1 \%$ infection rate and Class II Obesity and multilevel procedures as independent risk factors.

Table I: General Characteristics of 299 Patients Who Underwent Three-Column Osteotomy for Complex Spine Deformity

\begin{tabular}{|c|c|c|c|}
\hline Characteristics & SSI & No SSI & p-value \\
\hline Number of cases & 15 & 278 & \\
\hline Mean age (years) & $57 \pm 14$ & $61 \pm 13$ & 0.310 \\
\hline Male sex (\%) & 40.0 & 35.3 & 0.708 \\
\hline \multicolumn{4}{|l|}{$\mathrm{BMI}$} \\
\hline$<30$ & $6(40.0)$ & 60.4 & \multirow{4}{*}{$0.030^{\star}$} \\
\hline 30 - 34.9 (Class I Obesity) & $2(13.3)$ & 22.7 & \\
\hline 35 - 39.9 (Class II Obesity) & $2(33.3)$ & 13.3 & \\
\hline 40+ (Class III Obesity) & 13.3 & 3.6 & \\
\hline Hypertension (\%) & 66.7 & 57.9 & 0.503 \\
\hline Smoker (\%) & 20.0 & 17.6 & 0.815 \\
\hline Diabetes (\%) & 13.3 & 10.8 & 0.672 \\
\hline COPD (\%) & 6.7 & 5.8 & 0.601 \\
\hline Steroid use (\%) & 13.3 & 6.8 & 0.293 \\
\hline Bleeding disorder (\%) & 13.3 & 4.0 & $0.138^{*}$ \\
\hline Dependent functional status (\%) & 6.7 & 6.5 & 1.00 \\
\hline
\end{tabular}

Type of deformity

\begin{tabular}{|c|c|c|c|}
\hline Acquired & 80.0 & 71.6 & \\
\hline Congenital & 0.0 & 2.5 & \\
\hline latrogenic & 6.7 & 14.0 & 0.698 \\
\hline Other & 13.3 & 6.8 & \\
\hline Post-traumatic & 0.0 & 5.0 & \\
\hline
\end{tabular}

ASA class

\begin{tabular}{cccc}
\hline $1(\%)$ & 0.0 & 1.1 & \\
\cline { 1 - 3 } $2(\%)$ & 6.7 & 33.5 & \multirow{2}{*}{$0.051^{*}$} \\
\cline { 1 - 3 } $3(\%)$ & 80.0 & 60.4 & \\
\cline { 1 - 3 } $4(\%)$ & 13.3 & 5.0 & \\
\cline { 1 - 3 } Anemia (\%) & 46.7 & 28.7 & $0.153^{*}$ \\
\cline { 1 - 3 } Mean preoperative albumin level & $3.7 \pm 0.8$ & $3.9 \pm 0.5$ & 0.435 \\
\hline
\end{tabular}

*Included in the multivariate model.
Similar to our findings, Sciubba et al. conducted a systematic review of the literature on complications after adult spinal deformity surgery and found a $3.2 \%$ risk of SSI after $3 \mathrm{CO}$ (52/1,625 patients) (23). Likewise, Bianco et al. reported a $7.6 \%$ risk after examining 423 patients who underwent $3 \mathrm{CO}$ (2). Surgery for deformity has been associated with a higher risk of SSI than for surgery for other diagnoses, and it is

Table II: Operative Characteristics of 293 Patients Who Underwent Three-Column Osteotomy for Complex Spine Deformity

\begin{tabular}{lccl}
\hline Characteristics & SSI & No SSI & p-value \\
\hline Number of cases & 15 & 278 & \\
\hline Blood transfusion (\%) & 73.3 & 76.6 & 0.770 \\
\hline Mean operative time (hours) & $6.9 \pm 2.2$ & $6.5 \pm 2.4$ & 0.584 \\
\hline Revision procedure (\%) & 13.3 & 27.3 & 0.369 \\
\hline Thoracic 3CO (\%) & 26.7 & 26.6 & 1.00 \\
\hline Multilevel 3CO (\%) & 40.0 & 13.3 & $0.013^{*}$ \\
\hline Pelvic fixation (\%) & 40.0 & 27.7 & 0.377 \\
\hline
\end{tabular}

*Included in the multivariate model.

Table III: Multivariate Analysis

\begin{tabular}{|c|c|c|c|}
\hline Parameter & Odds ratio & $\begin{array}{c}95 \% \\
\text { confidence } \\
\text { interval }\end{array}$ & p-value \\
\hline $\mathrm{BMI}<30$ & $\begin{array}{c}1.00 \\
\text { (Reference) }\end{array}$ & - & - \\
\hline Class I Obesity & 1.22 & $0.21-6.90$ & 0.821 \\
\hline Class II Obesity & 4.98 & $1.24-19.94$ & $0.023^{*}$ \\
\hline Class III Obesity & 2.89 & $0.37-22.40$ & 0.309 \\
\hline Bleeding disorder & 2.36 & $0.31-17.46$ & 0.400 \\
\hline Acquired deformity & $\begin{array}{c}1.00 \\
\text { (Reference) }\end{array}$ & & \\
\hline Congenital & 1.00 & - & - \\
\hline latrogenic & 0.63 & $0.06-5.83$ & 0.690 \\
\hline Other & 2.70 & $0.45-16.15$ & 0.275 \\
\hline Post-traumatic & 1.00 & - & - \\
\hline ASA Class 1 & $\begin{array}{c}1.00 \\
\text { (Reference) }\end{array}$ & - & - \\
\hline ASA Class 2 & 0.16 & $0.01-2.35$ & 0.180 \\
\hline ASA Class 3 & 0.85 & $0.13-5.38$ & 0.864 \\
\hline ASA Class 4 & 1.00 & - & - \\
\hline Anemia & 1.96 & $0.56-6.89$ & 0.295 \\
\hline Multilevel $3 \mathrm{CO}$ & 4.71 & $1.30-16.94$ & $0.018^{*}$ \\
\hline
\end{tabular}

*Indicates statistical significance 
thought that the longer operative time and higher blood loss, among others, may contribute to this increased risk (20).

Class II obesity was found to increase the odds of SSI by a factor of 5 in our study. Commensurate with these findings, there is a great body of literature suggesting obesity significantly increases the risk of complications, including wound infection, after spinal surgery $(4,5,7,11,15,16,19,20,25,30)$. It has been suggested from preclinical data that obesity, particularly excess adipose tissue, causes an altered immune response to local surgical trauma and may be related to the increased incidence of local infection found in this population (6). Although obesity is not an absolute contraindication to spine surgery, it is reasonable to counsel patients on the increased risk for complications and perhaps encourage weight loss prior to undergoing surgery. However, whether this preoperative optimization would in fact contribute to decrease the risk of SSI is unknown, and further research is needed before establishing definitive conclusions.

Multilevel 3CO was also found to be a significant predictor of $\mathrm{SSI}$ in the present investigation. Bianco et al. also reported that multilevel $3 \mathrm{CO}$ had a significantly higher rate of perioperative complications compared to single $3 \mathrm{CO}(56 \%$ vs. $38 \%, p=0.040)(2)$. The higher risk of wound infection could be attributed to a longer incision and increased blood loss (2), though this cannot directly be assessed using the NSQIP database. Additionally, the more extensive tissue trauma of multilevel osteotomy compared to single-level osteotomy may account for the higher incidence of SSI, given that excessive/ prolonged retractor use and excessive use of electrocautery, for example, have been found to increase the risk of wound infection (9). Other risk factors associated with complications after deformity surgery (including 3CO) include smoking, hypertension, age above 60, thoracic osteotomy, major blood loss, and duration of symptoms $(2,26)$. Lastly, the cost of spine complications associated with deformity operations is not inconsequential. In a study performed by Hostin et al., the cost of managing a spinal infection for deformity operations ranged from $\$ 15,817$ to $\$ 38,701$ (29).

There are several limitations to this investigation, including the lack of spine-surgery specific data (including radiographic parameters, health-related quality of life outcomes, and others) and the use of CPT/ICD-9 codes to identify patients and procedures, which carries a risk of miscoding. Although data regarding readmissions/reoperations is available, data on antibiotic treatment is unfortunately not available for review. Nonetheless, NSQIP provides prospective and validated data, which allows for risk-adjusted analyses.

\section{- CONCLUSION}

Three-column osteotomy for spinal deformity correction is a complex procedure with a 30-day surgical site infection risk of approximately $5.1 \%$. Patients with Class 2 obesity and patients undergoing multilevel osteotomy may have a significantly higher risk of wound infection, which required reoperation for washout in $67 \%$ of the cases in this study.

\section{DISCLOSURE}

The American College of Surgeons National Surgical Quality Improvement Program and the hospitals participating in the ACS NSQIP are the source of the data used herein; they have not verified and are not responsible for the statistical validity of the data analysis or the conclusions derived by the authors.

\section{REFERENCES}

1. Abbey DM, Turner DM, Warson JS, Wirt TC, Scalley RD: Treatment of postoperative wound infections following spinal fusion with instrumentation. J Spinal Disord 8(4):278-283, 1995

2. Bianco K, Norton R, Schwab F, Smith JS, Klineberg E, Obeid I, Mundis G Jr, Shaffrey Cl, Kebaish K, Hostin R, Hart R, Gupta MC, Burton D, Ames C, Boachie-Adjei O, Protopsaltis TS, Lafage V; International Spine Study Group: Complications and intercenter variability of three-column osteotomies for spinal deformity surgery: A retrospective review of 423 patients. Neurosurg Focus 36(5):E18, 2014

3. Calderone RR, Garland DE, Capen DA, Oster H: Cost of medical care for postoperative spinal infections. Orthop Clin North Am 27(1):171-182, 1996

4. De la Garza-Ramos R, Bydon M, Abt NB, Sciubba DM, Wolinsky JP, Bydon A, Gokaslan ZL, Rabin B, Witham TF: The impact of obesity on short- and long-term outcomes after lumbar fusion. Spine (Phila Pa 1976) 40(1):56-61, 2015

5. Elsamadicy AA, Adogwa O, Vuong VD, Mehta Al, Vasquez $\mathrm{RA}$, Cheng J, Karikari IO, Bagley CA: Patient BMI is an independent predictor of 30-day hospital readmission after elective spine surgery. World Neurosurg 96:148-151, 2016

6. Falagas ME, Kompoti M: Obesity and infection. Lancet Infect Dis 6(7):438-446, 2006

7. Fang $\mathrm{A}, \mathrm{Hu}$ SS, Endres N, Bradford DS: Risk factors for infection after spinal surgery. Spine (Phila Pa 1976) 30(12): 1460-1465, 2005

8. Hassanzadeh $\mathrm{H}$, Jain A, El Dafrawy $M H$, Ain MC, Mesfin A, Skolasky RL, Kebaish KM: Three-column osteotomies in the treatment of spinal deformity in adult patients 60 years old and older: Outcome and complications. Spine (Phila Pa 1976) 38(9):726-731, 2013

9. Hegde V, Meredith DS, Kepler CK, Huang RC: Management of postoperative spinal infections. World J Orthop 3(11):182189, 2012

10. Iyer S, Nemani VM, Kim HJ: A review of complications and outcomes following vertebral column resection in adults. Asian Spine J 10(3):601-609, 2016

11. Jackson KL 2nd, Devine JG: The effects of obesity on spine surgery: A systematic review of the literature. Global Spine J 6(4):394-400, 2016

12. Ji X, Chen H, Zhang Y, Zhang L, Zhang W, Berven S, Tang $P$ : Three-column osteotomy surgery versus standard surgical management for the correction of adult spinal deformity: A cohort study. J Orthop Surg Res 10:23, 2015

13. Kim SS, Cho BC, Kim JH, Lim DJ, Park JY, Lee BJ, Suk SI: Complications of posterior vertebral resection for spinal deformity. Asian Spine J 6(4):257-265, 2012 
14. Lenke LG, Newton PO, Sucato DJ, Shufflebarger HL, Emans JB, Sponseller PD, Shah SA, Sides BA, Blanke KM: Complications after 147 consecutive vertebral column resections for severe pediatric spinal deformity: A multicenter analysis. Spine (Phila Pa 1976) 38(2):119-132, 2013

15. Lingutla KK, Pollock R, Benomran E, Purushothaman B, Kasis A, Bhatia CK, Krishna M, Friesem T: Outcome of lumbar spinal fusion surgery in obese patients: A systematic review and meta-analysis. Bone Joint J 97-B(10):1395-1404, 2015

16. Manoharan SR, Baker DK, Pasara SM, Ponce B, Deinlein D, Theiss SM: Thirty-day readmissions following adult spinal deformity surgery: An analysis of the National Surgical Quality Improvement Program (NSQIP) database. Spine J 16(7):862866, 2016

17. O'Neill KR, Lenke LG, Bridwell KH, Neuman BJ, Kim HJ, Archer KR: Factors associated with long-term patientreported outcomes after three-column osteotomies. Spine J 15(11):2312-2318, 2015

18. Olsen MA, Mayfield J, Lauryssen C, Polish LB, Jones M, Vest $\mathrm{J}$, Fraser VJ: Risk factors for surgical site infection in spinal surgery. J Neurosurg 98 Suppl 2:149-155, 2003

19. Patel N, Bagan B, Vadera S, Maltenfort MG, Deutsch $H$, Vaccaro AR, Harrop J, Sharan A, Ratliff JK: Obesity and spine surgery: Relation to perioperative complications. J Neurosurg Spine 6(4):291-297, 2007

20. Pull ter Gunne AF, Cohen DB: Incidence, prevalence, and analysis of risk factors for surgical site infection following adult spinal surgery. Spine (Phila Pa 1976) 34(13):1422-1428, 2009

21. Pull ter Gunne AF, van Laarhoven CJ, Cohen DB: Incidence of surgical site infection following adult spinal deformity surgery: An analysis of patient risk. Eur Spine J 19(6):982-988, 2010

22. Scheer JK, Lafage V, Smith JS, Deviren V, Hostin R, McCarthy IM, Mundis GM, Burton DC, Klineberg E, Gupta MC, Kebaish KM, Shaffrey Cl, Bess S, Schwab F, Ames CP; International Spine Study Group: Impact of age on the likelihood of reaching a minimum clinically important difference in 374 three-column spinal osteotomies: Clinical article. J Neurosurg Spine 20(3):306-312, 2014
23. Sciubba DM, Yurter A, Smith JS, Kelly MP, Scheer JK, Goodwin CR, Lafage V, Hart RA, Bess S, Kebaish K, Schwab F, Shaffrey $\mathrm{Cl}$, Ames CP; International Spine Study Group (ISSG): A comprehensive review of complication rates after surgery for adult deformity: A reference for informed consent. Spine Deformity 3(6):575-594, 2015

24. Singh MK, Ibrahimi DM, Shaffrey CI, Smith JS: Pedicle subtraction osteotomy. In: Wang Y, Boachie-Adjei O, Lenke L, (eds), Spinal Osteotomy. Dordrecht: Springer, 2015:89-110

25. Soroceanu A, Burton DC, Diebo BG, Smith JS, Hostin $\mathrm{R}$, Shaffrey $\mathrm{Cl}$, Boachie-Adjei O, Mundis GM Jr, Ames C, Errico TJ, Bess S, Gupta MC, Hart RA, Schwab FJ, Lafage V; International Spine Study Group: Impact of obesity on complications, infection, and patient-reported outcomes in adult spinal deformity surgery. J Neurosurg Spine 23(5): $656,664,2015$

26. Soroceanu A, Burton DC, Oren JH, Smith JS, Hostin R, Shaffrey $\mathrm{Cl}$, Akbarnia BA, Ames CP, Errico TJ, Bess S, Gupta MC, Deviren V, Schwab FJ, Lafage V; International Spine Study Group: Medical complications after adult spinal deformity surgery: Incidence, risk factors, and clinical impact. Spine (Phila Pa 1976) 41(22):1718-1723, 2016

27. Sun X, Zhu ZZ, Chen X, Liu Z, Wang B, Qiu Y: Posterior double vertebral column resections combined with satellite rod technique to correct severe congenital angular kyphosis. Orthop Surg 8(3):411-414, 2016

28. Wagner SC, Lehman RAJ, Lenke L: Posterior vertebral column resection (VCR) for complex spinal deformities. In: Wang Y, Boachie-Adjei O, Lenke L (eds), Spinal Osteotomy. Dordrecht: Springer, 2015:89-110

29. Yeramaneni S, Robinson C, Hostin R: Impact of spine surgery complications on costs associated with management of adult spinal deformity. Curr Rev Musculoskelet Med 9(3):327-332, 2016

30. Yuan K, Chen HL: Obesity and surgical site infections risk in orthopedics: A meta-analysis. Int J Surg 11(5):383-388, 2013 